\title{
THE MORPHOMETRY AND PATHOLOGICAL ANATOMY OF THE LUMBAR SPINE IN SOUTH AFRICAN NEGROES AND CAUCASOIDS WITH SPECIFIC REFERENCE TO SPINAL STENOSIS
}

\author{
Steve Eisenstein, Johannesburg, South Africa
}

From the Department of Orthopaedic Surgery, University of Witwatersrand, Johannesburg

\begin{abstract}
Direct measurements were made on 2,166 lumbar vertebrae of 433 adult negro and caucasoid skeletons. On statistical analysis, forty-five vertebrae in twenty-seven skeletons were found to be stenotic, the midsagittal diameter being the significantly reduced dimension. Whereas spinal stenosis syndromes are rare in South African negroes, the lumbar canal is marginally narrower in the negro. There is a uniformity of configuration and capacity of the lumbar spinal canal, which transcends race and sex. By a new method of determining the dorsal limit of the lumbar canal on lateral plain radiography, the overall average lower limit of normal of the mid-sagittal diameter is established at $\mathbf{1 5}$ millimetres, and of the transverse diameter $\mathbf{2 0}$ millimetres. Bony degenerative changes are more likely to cause neurological compression in the nerve root tunnel than in the spinal canal. The role of skeletal narrowing of the spinal canal as an exclusive cause of the spinal stenosis syndrome may have been exaggerated.
\end{abstract}

In recent years there has been a renewal of interest in spinal stenosis syndromes, especially in the extent to which the cauda equina may be compressed within the lumbar spinal canal by constriction or narrowing of the bony ring of the canal, in contrast to impingement by soft tissues. Anatomical stenosis of the lumbar canal was first suggested as a cause of these syndromes by Sarpyener (1945) and by Verbiest $(1954,1955)$.

The spinal stenosis syndrome, briefly, consists of low back pain, usually in an adult approaching middle age, accompanied by "claudication" in the lower limbs. Classically, the patient suffers pain, weakness and numbness in the lower limbs on walking, and relief cannot be achieved merely by standing and resting; the patient finds it necessary to undo his lumbar lordosis by bending or crouching. There may be objective neurological signs such as loss of a tendon jerk or changes in sensibility. These features are even more suggestive if the peripheral circulation is normal.

Narrowing of the spinal canal may be developmental, or it may be the consequence of degenerative changes from ageing, injury or disease, or of spinal operations.

This investigation is concerned mainly with developmental spinal stenosis. In the management of patients with cauda equina compression, several questions kept recurring: What constitutes spinal stenosis, and is developmental stenosis as common as some authors suggest? How does one establish the canal boundaries radiographically and what is the lower limit of normal? Where is the narrowest part of the lumbar canal? Why is the spinal stenosis syndrome rare in the South African negroid, and are there ethnic differences in spinal dimensions? In degenerative spinal stenosis, where does neurological compression occur? An anatomical study was undertaken in an attempt to find the answers.

\section{MATERIALS AND METHODS}

Four hundred and forty-three adult skeletons from the Raymond Dart Collection, Department of Anatomy, were examined. Of these, 113 are "white" caucasoid (seventy-eight male, thirty-five female), 162 are South African Zulu negroid (108 male, fifty-four female), and 168 are South African Sotho negroid (106 male, sixty-two female). Age at death ranged from sixteen to ninety-six years, averaging fifty years. Forty-nine vertebrae were missing or damaged, leaving 2,166 complete vertebrae available for study.

The largest previous similar study involved only fifty-one skeletons, all caucasoid (Huizinga, Heiden and Vinken 1952).

Vertebral measurement-The spinal canal and vertebral body of each vertebra were measured with a vernier caliper in transverse and antero-posterior diameters, as described by Jones and Thomson (1968). The antero-posterior or midsagittal distance of the spinal canal was measured at one point only, where this dimension is least, namely near the canal's upper limit, opposite a slight anterior bulge on the posterior wall of the canal in the midline. The transverse diameter of the canal is taken as the greatest interpedicular distance.

The mid-sagittal antero-posterior diameter of the body was measured at mid-height, to exclude discrepancies caused by border osteophytes. The transverse diameter of the body is taken as the greatest mid-waist distance.

Steve Eisenstein, F.R.C.S., Department of Orthopaedic Surgery, Medical School, Esselen Street, Johannesburg, South Africa. 
The information thus obtained was subjected to statistical analysis.

Radiological measurement-Fifty-five vertebrae of eleven skeletons were radiographed in the antero-posterior and lateral planes, the vertebrae being suspended in sponge blocks so as to mimic as closely as possible the positions of vertebrae in a patient undergoing radiography of the lumbar spine. All radiographs were taken with the Roentgen tube 110 centimetres from the plate, by universal convention.

Radio-opaque metal markers were placed within the spinal canals of the same fifty-five vertebrae, at the midsagittal posterior limit. Measurements made on the vertebrae, as described above, were repeated on the radiographs.

Magnification factors were calculated for the anteroposterior and lateral views, in order to render the above information relevant in clinical practice.

Pathological anatomy-Observations were made on the skeletal material to determine the nature and incidence of alterations in the anatomy, whether pathological or normal variation, including "arthritic" osteophytosis, lumbarisation of the first sacral vertebra, sacralisation of the fifth lumbar vertebra, persistence of apophysial joints in the sacrum, sacro-transverse joints (patent or ankylosed), sacro-iliac joint fusion, stress fractures of the pars inter-articularis (spondylolysis), spina bifida, wedge compression of vertebral bodies, and trefoil or "maple-leaf" configuration of the lumbar canal.

\section{RESULTS}

In all, 2,166 vertebrae in two races and both sexes were measured in the transverse and mid-sagittal diameters of the canal, and of the vertebral body (Table I). The transverse or interpedicular diameter of the canal averaged 23 millimetres and was remarkably constant from the first to the fifth lumbar vertebra, in both sexes and both races. The average lower limit of normal was 18 millimetres. Eighteen lumbar vertebrae ( 0.8 per cent) were stenotic in this dimension. No transverse diameter was less than 16 millimetres.

The mid-sagittal diameter, however, was the narrower dimension, the average being 16 millimetres, with a lower limit of normal of 13 millimetres. The range of normal in this diameter is again remarkably constant across race and sex. The vertebrae statistically "stenotic" in the mid-sagittal diameter numbered twenty-eight out of 2,166 ( 1.3 per cent), but the most interesting finding was that even these stenotic vertebrae were only marginally below the lower limit of normal: none was less than 11 millimetres in the mid-sagittal diameter. There was no example of dramatically marked stenosis in the entire series.

Altogether, twenty-eight of the 443 skeletons $(6.3 \mathrm{per}$ cent) showed stenosis in one or other dimension of forty-six lumbar vertebrae. Stenosis is more than twice as frequent in the mid-sagittal plane.

Two of the twenty-eight skeletons had vertebrae which were stenotic in both diameters. The presence of one stenotic vertebra implies a 60 per cent chance of a second stenotic vertebra being present in the same spine.

Tables II and III show the incidence of stenosis according to race, sex and vertebral level. The structural alteration causing mid-sagittal stenosis is an increase in the interlaminar angle (shortening of the laminae), rather than a shortening of the pedicles.

Figure 1 shows the position of radio-opaque markers against the posterior boundary of the canal, at that point where the antero-posterior dimension is shortest. These

TABLE I

Mean lumbar Vertebral Diameters (millimetres)

\begin{tabular}{|c|c|c|c|c|c|c|c|}
\hline & & & L. 1 & L. 2 & L. 3 & L.4 & L. 5 \\
\hline \multirow{4}{*}{ Caucasoid male } & \multirow{2}{*}{ Canal } & A.P. & & 17 & 16 & 16 & 18 \\
\hline & & I.P. & 23 & 24 & 23 & 24 & 26 \\
\hline & \multirow{2}{*}{ Body } & A.P. & 31 & 32 & 33 & 34 & 33 \\
\hline & & T.V. & 39 & 40 & 43 & 44 & 46 \\
\hline \multirow{4}{*}{ Zulu Negroid male } & \multirow{2}{*}{ Canal } & A.P. & & 15 & 15 & 15 & 16 \\
\hline & & I.P. & 21 & 22 & 22 & 23 & 26 \\
\hline & \multirow{2}{*}{ Body } & A.P. & & 30 & 32 & 33 & 32 \\
\hline & & T.V. & 39 & 40 & 42 & 44 & 45 \\
\hline \multirow{4}{*}{ Sotho Negroid male } & \multirow{2}{*}{ Canal } & A.P. & & 15 & 14 & 15 & 16 \\
\hline & & I.P. & 21 & 21 & 22 & 23 & 25 \\
\hline & \multirow{2}{*}{ Body } & A.P. & 27 & 29 & 31 & 32 & 33 \\
\hline & & T.V. & 38 & 39 & 41 & 43 & 44 \\
\hline \multirow{4}{*}{ Caucasoid female } & \multirow{2}{*}{ Canal } & A.P. & & 17 & 17 & 16 & 18 \\
\hline & & I.P. & 22 & 22 & 23 & 23 & 25 \\
\hline & \multirow{2}{*}{ Body } & A.P. & 27 & 27 & 29 & 29 & 30 \\
\hline & & T.V. & 34 & 35 & 37 & 39 & 42 \\
\hline \multirow{4}{*}{ Zulu Negroid female } & \multirow{2}{*}{ Canal } & A.P & & 16 & 15 & 16 & 16 \\
\hline & & I.P. & 20 & 21 & 21 & 22 & 24 \\
\hline & \multirow{2}{*}{ Body } & A.P & & 26 & 28 & 30 & 31 \\
\hline & & T.V & 35 & 37 & 38 & 41 & 43 \\
\hline \multirow{4}{*}{ Sotho Negroid female } & \multirow{2}{*}{ Canal } & A.P & & 16 & 15 & 15 & 16 \\
\hline & & T.V. & 20 & 20 & 21 & 22 & 24 \\
\hline & \multirow{2}{*}{ Body } & A.P & 25 & 26 & 28 & 30 & 31 \\
\hline & & T.V & 34 & 36 & 38 & 40 & 42 \\
\hline
\end{tabular}

A.P. = Antero-posterior $/$ Mid-sagittal

I.P. = Interpedicular

T.V. $=$ Transverse

positions are more posterior than most clinicians would estimate, and were reproduced consistently in the eleven skeletons radiographed.

Figure 2 is a tracing of Figure 1 and shows how these positions may be calculated with very little practice; from the first to the fourth lumbar vertebrae they lay opposite the cephalad half of the body of the vertebra, on a line joining the apex of the superior facet and the 
inverted apex of the inferior facet. For the fifth lumbar vertebra the posterior limit was found to be just anterior to a well-demarcated radiolucent lake in the spinous process, and is still more posterior than usually estimated.

A magnification factor of 1.23 was established for the standard lateral radiograph which gave an overall moderate or severe osteophytosis was found often and consistently got worse from the first to the fifth lumbar vertebrae; the first cervical vertebrae were impressively unaffected, even in the worst cases.

Severity of osteophytosis was graded as mild, moderate or severe.

TABLE II

TransVerse (INTERPEDicular) Diameters

\begin{tabular}{|c|c|c|c|c|c|}
\hline & \multirow[b]{2}{*}{$\begin{array}{c}\text { Mean } \\
\text { (millimetres) }\end{array}$} & \multirow[b]{2}{*}{$\begin{array}{l}\text { Range of normal } \\
\text { (millimetres) }\end{array}$} & \multicolumn{3}{|c|}{ Stenosis } \\
\hline & & & $\begin{array}{l}\text { Number of } \\
\text { stenotic vertebrae }\end{array}$ & $\begin{array}{l}\text { Percentage incidence } \\
\text { in skeletal population }\end{array}$ & Level \\
\hline Caucasoid male & 24 & $19-29$ & 1 & $1 \cdot 3$ & L.1 \\
\hline Zulu Negroid male & 23 & $17-28$ & 一 & - & 一 \\
\hline Sotho Negroid male & 22 & $19-26$ & 6 in 3 skeletons & $2 \cdot 8$ & $\begin{array}{l}\text { L. } 1 \text { (2) } \\
\text { L.3 (3) } \\
\text { L.5 (1) }\end{array}$ \\
\hline Caucasoid female & 23 & $18-28$ & - & - & 一 \\
\hline Zulu Negroid female & 22 & $18-26$ & 2 in 2 skeletons & $3 \cdot 7$ & L.1 (2) \\
\hline Sotho Negroid female & 21 & $18-25$ & 9 in 3 skeletons & $4 \cdot 8$ & $\begin{array}{l}\text { L. } 1 \text { (2) } \\
\text { L.2 (2) } \\
\text { L.3 (1) } \\
\text { L.4 (2) } \\
\text { L.5 (2) }\end{array}$ \\
\hline \multicolumn{3}{|c|}{$\begin{array}{r}\text { Dverall lower limit of normal-skeletal }=18 \text { millimetres } \\
\text { —radiological }=20 \text { millimetres }\end{array}$} & 18 in 9 skeletons & $2 \cdot 0$ & \\
\hline
\end{tabular}

TABLE III

ANTERO-Posterior (Midsagittal) Diameters

\begin{tabular}{|c|c|c|c|c|c|}
\hline & \multirow[b]{2}{*}{$\underset{\text { (millimetres) }}{\text { Mean }}$} & \multirow[b]{2}{*}{$\begin{array}{l}\text { Range of normal } \\
\text { (millimetres) }\end{array}$} & \multicolumn{3}{|c|}{ Stenosis } \\
\hline & & & $\begin{array}{l}\text { Number of } \\
\text { stenotic vertebrae }\end{array}$ & $\begin{array}{l}\text { Percentage incidence } \\
\text { in skeletal population }\end{array}$ & Level \\
\hline Caucasoid male & 17 & $14-20$ & 10 in 6 skeletons & $7 \cdot 7$ & $\begin{array}{l}\text { L.1 (2) } \\
\text { L.3 (3) } \\
\text { L. } 4 \text { (4) } \\
\text { L. } 5 \text { (1) }\end{array}$ \\
\hline Zulu Negroid male & 16 & $12-20$ & 9 in 7 skeletons & 6.5 & $\begin{array}{l}\text { L.3 (4) } \\
\text { L.4 (4) } \\
\text { L. } 5 \text { (1) }\end{array}$ \\
\hline Sotho Negroid male & 15 & $12-19$ & 2 in 2 skeletons & 1.9 & $\begin{array}{l}\text { L.2 (1) } \\
\text { L.4 (1) }\end{array}$ \\
\hline Caucasoid female & 17 & $13-21$ & 1 & $2 \cdot 9$ & L.4 (1) \\
\hline Zulu Negroid female & 16 & $13-19$ & 3 in 2 skeletons & $3 \cdot 7$ & $\begin{array}{l}\text { L. } 4(2) \\
\text { L.5 (1) }\end{array}$ \\
\hline Sotho Negroid female & 15 & $12-19$ & 3 in 3 skeletons & $4 \cdot 8$ & $\begin{array}{l}\text { L.1 (1) } \\
\text { L.2 (1) } \\
\text { L. } 4 \text { (1) }\end{array}$ \\
\hline \multicolumn{3}{|c|}{$\begin{array}{r}\text { Overall lower limit of normal-skeletal }=13 \text { millimetres } \\
\text {-radiological }=15 \text { millimetres }\end{array}$} & 28 in 21 skeletons & $4 \cdot 7$ & \\
\hline
\end{tabular}

lower limit of normal of 15 millimetres for the midsagittal diameter of the canal. The magnification factor for the antero-posterior view was $1 \cdot 14$, giving an overall lower limit of normal of 20 millimetres for the interpedicular diameter.

As would be expected in a cadaver population, mild,
"Mild" osteophytosis implies minor bony projections from the sharp edges of the vertebral body, curling at the edges of the articular facets, without significant change in the size or shape of the articular surfaces. "Moderate" osteophytosis implies major bony projections from the edges of the vertebral body even to the 
extent of "parrot-beaking", but without alteration of the normal contours of the body at mid-height; the edges of the articular facets are obviously overgrown and scalloped, but the apophysial joint lines are easily discernible in the articulated skeleton.

"Severe" osteophytosis implies new bone formation around the vertebral body so gross as to increase its girth, and fusion of osteophytes between succeeding

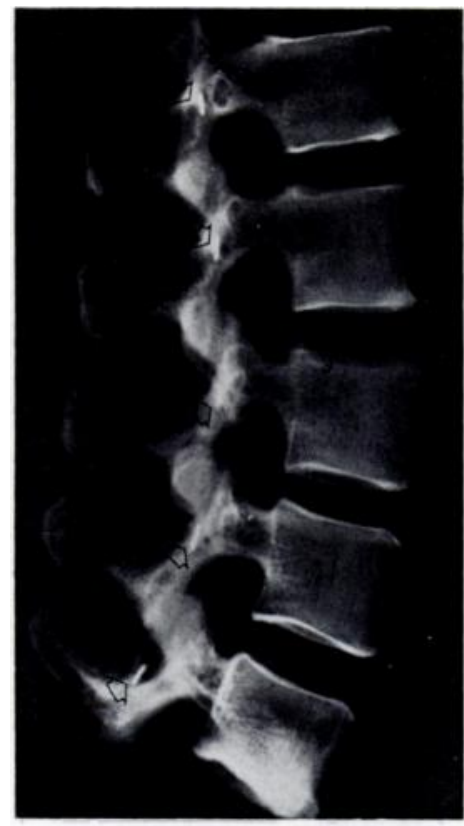

Fig. 1
Table IV shows the incidence and distribution of osteophytosis in each group.

Osteophytosis occurred about half as often in the negroid Zulu male as in the other five groups.

In 169 skeletons showing mild to gross osteophytosis, only six had evidence of canal encroachment by facet osteophytes in one or more vertebrae; three others showed canal encroachment by body osteophytes.

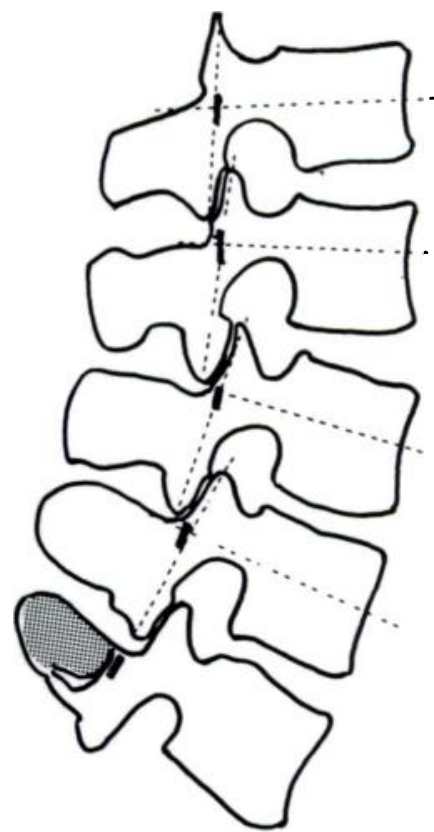

FIG. 2

Figure 1-Lateral radiograph of macerated spine with markers to show posterior limits of spinal canal. Figure 2-Tracing of Figure 1, illustrating method of determining posterior limits of spinal canal.

TABLE IV

OSTEOPHYTOSIS

\begin{tabular}{|l|c|c|c|l|}
\hline & $\begin{array}{c}\text { Average age of } \\
\text { whole group in years }\end{array}$ & $\begin{array}{c}\text { Average age in years } \\
\text { with osteophytosis }\end{array}$ & $\begin{array}{l}\text { Percentage incidence } \\
\text { of skeletal population }\end{array}$ & \multicolumn{1}{|c|}{ Site distribution } \\
\hline Caucasoid male & 66 & 70 & 50 & Facet predominance \\
\hline Zulu Negroid male & 49 & 58 & $25 \cdot 2$ & Facet predominance \\
\hline Sotho Negroid male & 41 & 53 & $43 \cdot 4$ & $\begin{array}{l}\text { Even between bodies alone } \\
\text { and facet/body combination }\end{array}$ \\
\hline Caucasoid female & 65 & 70 & $51 \cdot 4$ & $\begin{array}{l}\text { Facet/body combination } \\
\text { predominance }\end{array}$ \\
\hline Zulu Negroid female & 47 & 58 & $55 \cdot 6$ & $\begin{array}{l}\text { Even between facets alone } \\
\text { and facet/body combination }\end{array}$ \\
\hline Sotho Negroid female & 40 & 52 & $43 \cdot 5$ & $\begin{array}{l}\text { Facet/body combination } \\
\text { predominance }\end{array}$ \\
\hline
\end{tabular}

bodies is common; the articular facets resemble lettuce leaves, and in the articulated skeleton the apophysial joint lines are obscured and overlap and interlock (Fig. 3). The articular surfaces are distorted and enlarged, extending on to the superior surface of the laminae, resulting in a "faceto-laminar" joint. With rare exceptions, there are significant curled projections encroaching on the nerve root tunnel from the postero-lateral corners of the vertebral body (Fig. 4).
Posterior lipping, which might have been clinically significant, was thus a rare finding. In two skeletons there were obvious osteophytic changes in the facet-joints confined to one side only of all five lumbar vertebrae.

The articular surface of the superior facet is curved from the medial to lateral side, and faces posteromedially, but this commonly accepted configuration was modified in a few skeletons; six had flat surfaces in the coronal plane, and eight had flat surfaces in the sagittal 


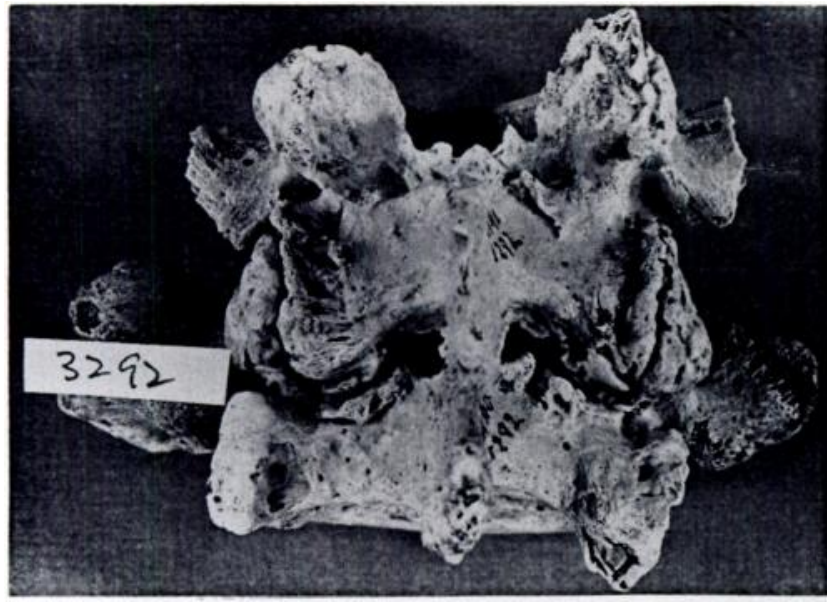

Fig. 3

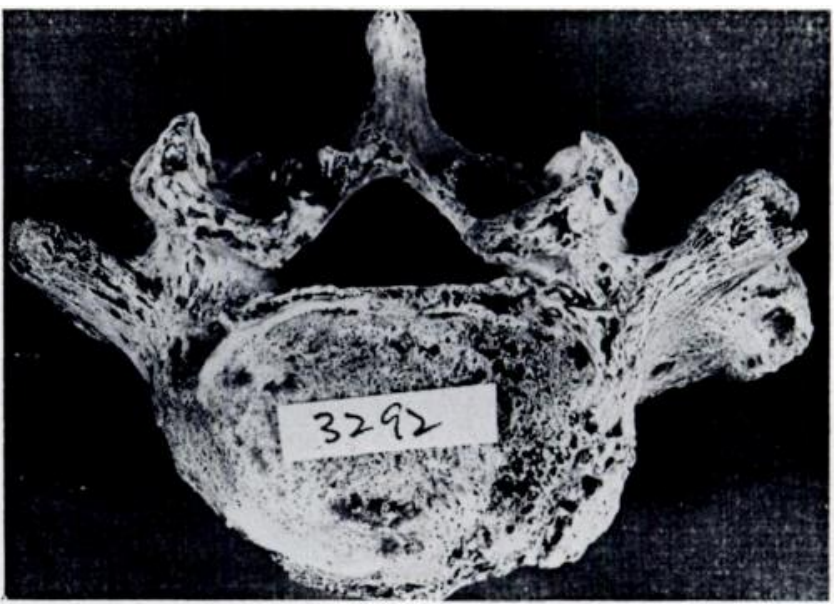

Fig. 4

Figure 3-Osteophytosis L.4-L.5 posterior intervertebral joints illustrating scalloping ("lettuce leaves") and "faceto-laminar" joints. Figure 4 - Osteophytic lipping of vertebral body showing encroachment laterally at nerve root tunnel.

plane. Only one of these skeletons, with coronal flattening, demonstrated osteophytosis of the facet-joints.

Trefoil configuration of the lumbar spinal canal has been considered a pathological alteration of the anatomy whereby facet-joint osteophytes encroached on the contents of the spinal canal. The trefoil shape was found in both races and both sexes in sixty-six skeletons ( 15 per cent), always in the fifth and occasionally in the fourth lumbar vertebrae.

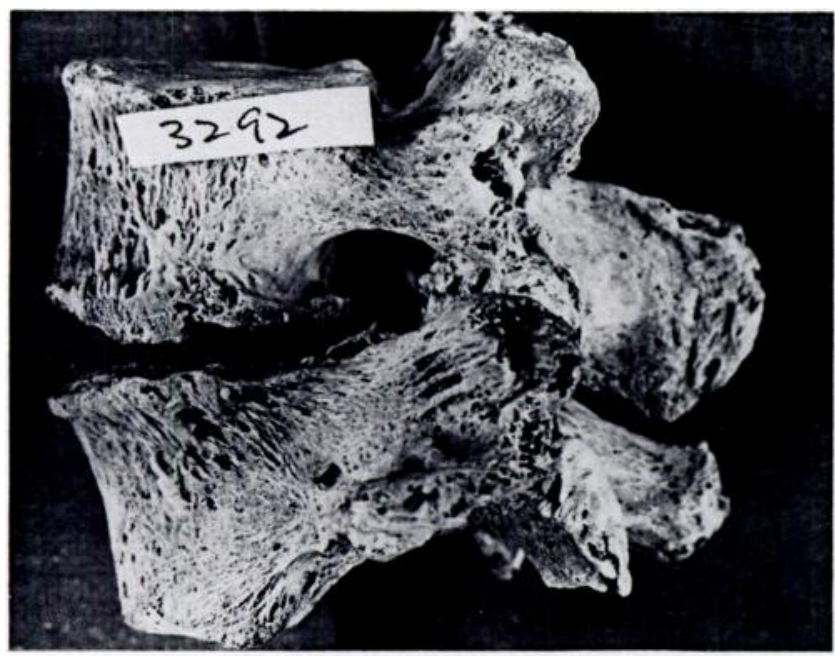

Fig. 5

Facet joint and body osteophytes projecting into nerve root tunnel.

Close examination of the affected vertebrae revealed that the encroachment into the usual triangular shape of the canal was caused by a localised thickening of the lamina, running in a vertical direction for the full vertical height of the lamina (Fig. 6). As described above, osteophytic encroachment on the normal shape of the spinal canal was an uncommon finding. The average age of skeletons showing laminar thickening was forty-six years. Fifteen per cent of these skeletons were associated with spinal canal stenosis as against 6.3 per cent for the whole sample.
Lumbarisation of the first sacral vertebra occurred in both races and sexes in nine skeletons ( 2 per cent).

Persistence of zygapophysial joints between the first and second sacral vertebrae was found in sixteen skeletons (3.6 per cent), in both races and sexes. It is possible that this is the least form of lumbarisation.

True sixth lumbar vertebrae occurred in two skeletons, both Sotho negroes. There was only one instance (in a Zulu negro) of a true transitional lumbo-sacral vertebra.

Sacralisation of the fifth lumbar vertebra occurred in eight skeletons (1.8 per cent): there was no instance of this in the caucasoid female group.

A sacro-transverse joint, whether patent or ankylosed, was found in ten skeletons ( 2.3 per cent). In most of these skeletons there was a notable reduction in the size of the lumbo-sacral apophysial facets on the side of the joint or ankylosis.

Ankylosis of the sacro-iliac joint occurred in ten skeletons $(2 \cdot 3$ per cent $)$. Both races were affected but all were males.

Spondylolysis, or stress fracture of the pars interarticularis, was present in ten skeletons in both races and sexes $(2 \cdot 3$ per cent), involving the fifth lumbar vertebra in nine and the fourth in one. The latter vertebra (Fig. 7) showed an ununited fracture on the left side only; the other nine vertebrae had bilateral fractures, and one of these had a completely bifid spinous process.

Spina bifida, resulting in a complete separation of left and right laminae, occurred in the lumbar vertebrae of only seven skeletons $(1.6$ per cent $)$.

Anterior wedge compression of the lumbar vertebral bodies occurred in only seventeen skeletons ( 3.8 per cent), and not at all in caucasoid females.

\section{DISCUSSION}

Developmental spinal stenosis-The mid-sagittal diameter of the lumbar spinal canal is the dimension in which the capacity of the canal is deficient, rather than in the 


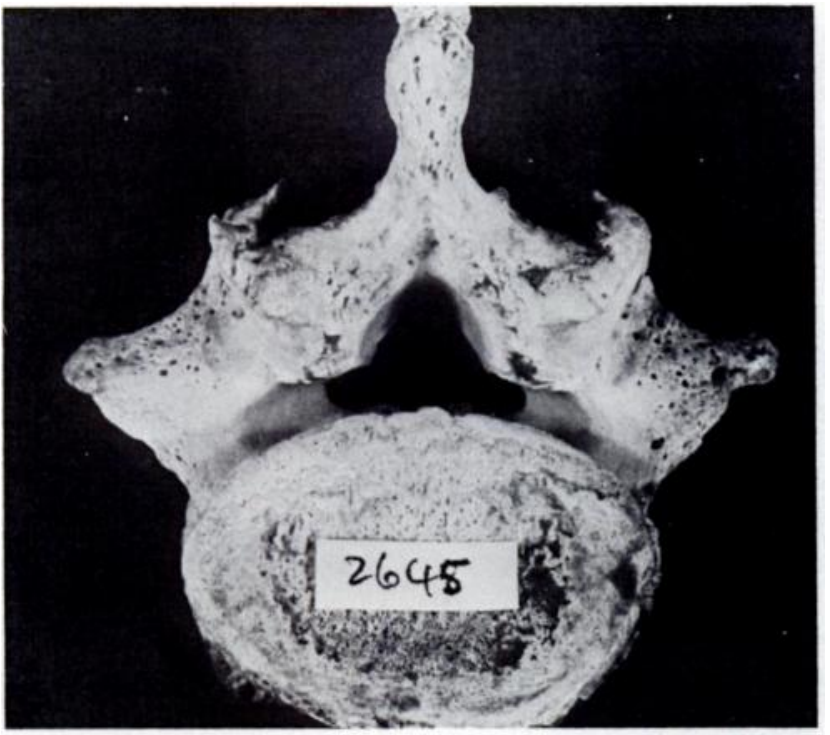

Fig. 6

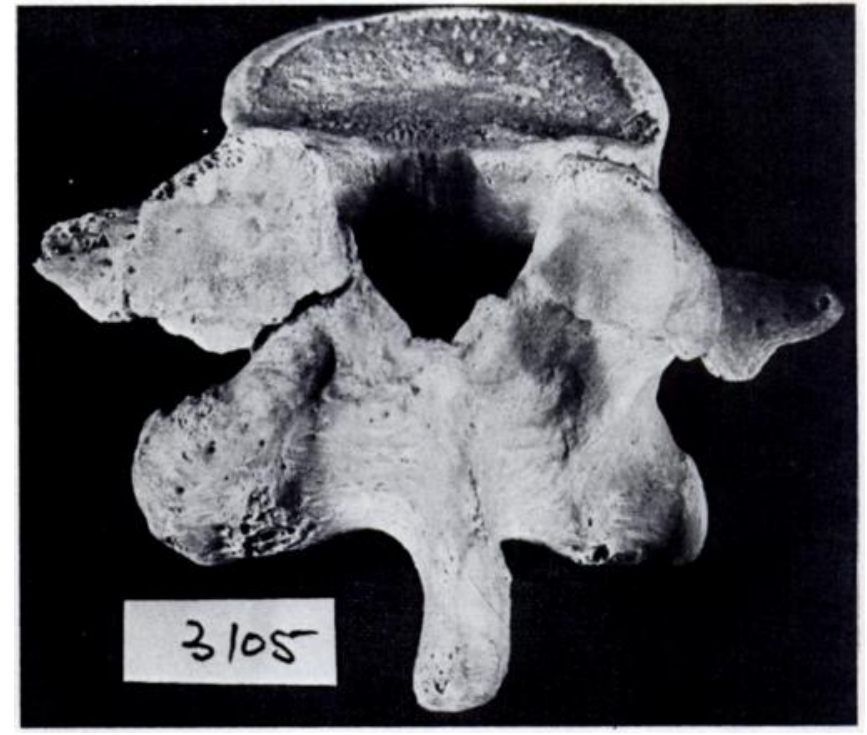

Fig. 7

Figure 6-Inferior aspect of fifth lumbar vertebra, showing laminar bars and trefoil shape of canal. Figure 7-Posterior aspect of L.4 showing ununited fracture of left pars interarticularis, and enlarged inferior facet on left.

transverse or interpedicular diameter. This finding confirms previous work (Verbiest 1954; Teng and Papatheodorou 1963; Schatzker and Pennal 1968; Dommisse 1974, 1975).

Twenty-eight skeletons (6.3 per cent) demonstrated stenosis of the lumbar spinal canal, 4.7 per cent in the mid-sagittal diameter and 2 per cent in the transverse diameter.

An incidence of stenosis of over 6 per cent appears at first to be a very high percentage for any population, but it is important to recognise that the forty-six vertebrae with dimensions that fell below the lower limit of normal were only very slightly subnormal. The shortest midsagittal diameter was 11 millimetres, where the lower limit of normal is 13 millimetres. The least transverse diameter was 16 millimetres, against a lower limit of normal of 18 millimetres. The "stenotic" vertebrae were but barely so.

The role of skeletal narrowing of the spinal canal, as an exclusive cause of the spinal stenosis syndrome, may have been exaggerated. Marginal stenosis may well predispose to cauda equina compression by secondary but minimal degenerative changes in bone and soft-tissue structures bordering the spinal canal and which may be overlooked clinically - a contention previously made by Clark (1969), which appears to be supported by this investigation.

An attempt was made to apply the concept of the Spinal Index of Jones and Thomson (1968), that is, the product of the canal diameters expressed as a ratio of the body diameters. Using their ratio of $1: 4.5$ as the lower limit of normal ("small") canal, it was found that 11 per cent of vertebrae would be regarded as stenotic, an unlikely possibility. In addition, many vertebrae considered stenotic by this calculation had obviously adequately capacious canals for accommodating the human spinal cord or cauda equina.
Attempting to establish a new range of a normal spinal index for the material under study, it was found that the standard deviation about the mean was so wide that the concept became irrelevant. Consequently, the concept of the spinal index is not considered valid when screening for spinal stenosis; it would seem to be preferable to concentrate on the absolute dimensions, especially the mid-sagittal diameter of the canal.

\section{Radiological projection}

Several references in the literature attest to the difficulty of determining the posterior or dorsal limit of the bony canal in the standard lateral view (Hinck, Hopkins and Clark 1965; Jones and Thomson 1968; Kirkaldy-Willis, Paine, Cauchoix and McIvor 1974; Verbiest 1975). There is no single radiographic landmark for this point, which is further obscured by the transverse processes, thus requiring the $x$-rays to pass through up to 8 centimetres of bone in this plane. The anterior mid-sagittal boundary of the canal, and the interpedicular limits, are well demarcated radiographically.

The present investigation has shown that the posterior border of the canal may be established by a simple extrapolation on the lateral radiograph, that is a point opposite the cephalad half of the vertebral body, on a line joining the apex of the superior apophysial joint and the inverted apex of the inferior apophysial joint of the same vertebra. For the fifth lumbar vertebra this point is more easily established, just anterior to the welldemarcated anterior limit of the radiolucent spinous process.

Figure 1 is a radiograph of a macerated dried skeleton, but the method described above can be applied without difficulty to clinical radiographs of good average quality.

With the bony canal measurable on radiographs 
with reasonable accuracy, and with the established magnification factor of 1.23 from skeleton to radiograph, it is possible to use standard radiographs as a primary screening investigation in suspected developmental spinal stenosis. The overall lower limit of normal in the mid-sagittal diameter for the five lumbar vertebrae in both sexes and races is 15 millimetres; and 20 millimetres for the interpedicular diameter.

The figure of 15 millimetres was found subsequently to be confirmed by previous work, where myelography was employed (Epstein, Epstein and Lavine 1962).

The shape of the lumbar canal-The lumbar spinal canal is not simply a truncated cone; in the antero-posterior dimension (Table I) it resembles a venturi tube, with a slightly narrow waist at the second, third and fourth lumbar vertebrae and flared at each end. The configuration is consistent across race and sex.

In the transverse plane, however, there is a steady increase in capacity from the first to the fifth lumbar vertebrae, again consistent across race and sex.

Racial differences-Where are the black patients with stenosis syndromes? There are no references in the literature. Personal communication with colleagues has revealed a handful of unconfirmed cases.

The tempting conclusion is that the South African negroid has a wider lumbar canal than the caucasoid. On the contrary, the negroid canal is marginally less capacious than the caucasoid in both sexes (Table I). The cause of caucasoid preponderance in stenosis syndromes should probably be sought in the soft-tissue structures bordering the canal.

The Zulu belong to a tribal subgroup, the Natal Nguni, and are ethnically and linguistically distinct from the Sotho, but cannot be said to be racially distinct. Studies of dentition, skull anthropometry and sacral morphology by workers in South Africa have not revealed significant differences between these two groups, and the present study lends further support to that finding. For practical purposes, these two groups may be pooled into a larger single South African Negro sample.

The metrical differences between the negro and caucasian groups, and between the sexes, are also insignificant.

\section{Degenerative spinal stenosis}

When one does a posterior decompression procedure for a stenosis syndrome in a middle-aged to elderly patient, one is impressed by the exuberant excrescences of bone that have grown around the facet joints and one is tempted to assume that these must encroach on the vertebral canal and compress its contents (KirkaldyWillis et al. 1974). This assumption is not supported by examination of the many skeletons demonstrating moderate to gross osteoarthritis (Fig. 3). Significant encroachment on the canal outline by vertebral body osteophytes was also uncommon and constituted no more than a "sharpening" of the usually rounded lateral corners of the canal. Lipping of the edges of the vertebral bodies was found to start laterally, away from the canal itself, but in the region of the nerve root tunnel (Figs. 4 and 5). Macnab (1975) has also refocused attention on the intervertebral foramen in this respect.

The evidence favours compression of the nerve roots in the nerve root tunnel rather than in the spinal canal. If this is indeed the case, why does a posterior decompression relieve the condition so dramatically? The literature contains several references to the need for a wide or laterally extensive decompression, in order to achieve success (Friedmann 1961; Jones and Thomson 1968; Schatzker and Pennal 1968; Clark 1969; Nelson 1973; Kirkaldy-Willis et al. 1974; Verbiest 1975). It is suggested, therefore, that such a procedure is successful because the nerve root tunnels are being partially decompressed and not because the spinal canal itself is laid open.

An objective grading of osteophytosis according to severity is not easily accomplished and must necessarily depend on the "eye of the beholder". The three grades employed in this study are a simplification of the four grades described by Nathan (1962). Grading is not important, except in the recognition of severe osteophytosis, which is frequently associated with significant bony projection into the nerve root tunnel from the postero-lateral corners of the vertebral body.

The varying incidence of osteophytosis in the different groups probably reflects the varying average ages of the skeletal samples, rather than their race or sex (Table IV). Generally, as expected, the incidence increased with age. It is not possible at this stage to account for the low incidence of osteophytosis in Zulu males.

The increased severity of osteophytosis in the lower lumbar vertebrae would be consistent with vertical loadbearing in the upright posture of man, complicated by normal lumbar lordosis (Nathan 1962).

The distribution of osteophytosis in the different groups does not conform to any pattern of race, sex or age.

The suggestion that osteophytosis is a defence mechanism in response to pressure, and not a pathological reaction per se (Nathan 1962) is teleological and therefore unsatisfactory. Certainly, the recurring pattern of buttressing, interlocking, and increased surface area of the facet-joints (Fig. 3) tempts one to make comparisons with the theory of building construction.

The pathogenesis of osteophyte formation remains an area for speculation, but age-related deterioration of all soft-tissue supports with ensuing instability and repeated minor periosteal and capsular stripping is an attractive mechanical concept.

\section{Trefoil configuration of the canal}

This alteration in the usual triangular shape of the lumbar canal, almost invariably at the fifth lumbar level, is seen as a variation of normal anatomy and not a pathological 
state causing compression. The lumbar canal at this level has to accommodate only the fifth lumbar and sacral nerve roots.

The low average age (forty-six years) and the low incidence of associated osteoarthritis favour a developmental variant rather than a degenerative change.

Canal size has, however, been assessed in two dimensions only, and it remains a possibility that laminar thickening impinges on sacral nerve roots. Certainly, skeletons with trefoil canals demonstrated developmental stenosis more than twice as frequently as the whole skeletal population ( 15 per cent as against 6.3 per cent) but, as with developmental stenosis, the trefoil shape is possibly of no consequence in the absence of additional compressive agents.

\section{Transitional variation}

Lumbarisation, sacralisation, transitional and sixth lumbar vertebrae, and persistence of zygapophysial joints in the sacrum, may all be regarded as developmental variations of normal anatomy at a crucial spinal junction: thirty-six skeletons (8 per cent) manifested such changes, which alone, are probably of no consequence. It is noteworthy, however, how frequently these variations, amongst others, are seen incidentally in patients, especially younger adults, presenting with backache. These variations, including spina bifida occulta, abnormal direction of articular facets, and sacro-transverse joints, may all indicate the "congenitally predisposed" lumbar spine-the predisposition to backache as a result of some overall mechanical instability and not arising from the anatomical variation alone.

\section{CONCLUSIONS}

From the direct measurements of 2,166 vertebrae in 443 skeletons in two race groups certain conclusions have been drawn. 1) In vertebrae considered to be stenotic, the antero-posterior diameter is the significantly reduced dimension. 2) The Spinal Index is not considered a valid indicator of stenosis. 3) The posterior limit of the lumbar canal can be determined on plain lateral radiography; the overall average lower limit of normal of the anteroposterior diameter of the lumbar canal is 15 millimetres, and of the transverse diameter, 20 millimetres. 4) The lumbar canal is narrowest at the second to fourth lumbar levels. 5) Degenerative changes may cause neurological compression in the nerve root tunnel rather than in the lumbar canal. 6) The lumbar canal is marginally less capacious in the negroid than in the caucasoid. 7) This preliminary survey suggests that the role of developmental narrowing of the spinal canal in the causation of the spinal stenosis syndrome may have been exaggerated. There is a uniformity of configuration and capacity of the lumbar spinal canal which transcends race and sex.

I am indebted to Professor Phillip V. Tobias, Professor George Dommisse and Professor Louis Solomon, for advice and encouragement.

\section{REFERENCES}

Clark, K. (1969) Significance of the small lumbar spinal canal: cauda equina compression syndromes due to spondylosis. Part 2: Clinical and surgical significance. Journal of Neurosurgery, 31, 495-498.

Dommisse, G. F. (1974) Personal communication.

Dommisse, G. F. (1975) Morphological aspects of the lumbar spine and lumbosacral region. Orthopedic Clinics of North America, 6, 163-175.

Epstein, J. A., Epstein, B. S., and Lavine, L. (1962) Nerve root compression associated with narrowing of the lumbar spinal canal. Journal of Neurology, Neurosurgery and Psychiatry, N.S., 25, 165-176.

Friedmann, E. (1961) Narrowing of the spinal canal due to thickened lamina, a cause of low-back pain and sciatica. Clinical Orthopaedics, 21, 190-197.

Hinck, V. C., Hopkins, C. E., and Clark, W. M. (1965) Sagittal diameter of the lumbar spinal canal in children and adults. Radiology, 85, 929-937.

Huizinga, J., Heiden, J. A. v. d., and Vinken, P. J. J. G. (1952) The human lumbar vertebral canal: a biometric study. Proceedings of the Section of Sciences. Koninklijke Nederlandse akademie van wetenschappen, series C, 55, 22-33.

Jones, R. A. C., and Thomson, J. L. G. (1968) The narrow lumbar canal. Journal of Bone and Joint Surgery, 50-B, 595-605.

Kirkaldy-Willis, W. H., Paine, K. W. E., Cauchoix, J., and Mclvor, G. (1974) Lumbar spinal stenosis. Clinical Orthopaedics and Related Research, 99, 30-50.

Macnab, I. (1975) Surgical treatment of degenerative disc disease of the lumbar spine. In Recent Advances in Orthopaedics. Number 2, pp. 1-33. Edited by B. McKibbin. Edinburgh, London and New York: Churchill Livingstone.

Nathan, H. (1962) Osteophytes of the vertebral column. Journal of Bone and Joint Surgery, 44-A, 243-268.

Nelson, M. A. (1973) Lumbar spinal stenosis. Journal of Bone and Joint Surgery, 55-B, 506-512.

Sarpyener, M. A. (1945) Congenital stricture of the spinal canal. Journal of Bone and Joint Surgery, 27, 70-79.

Schatzker, J., and Pennal, G. F. (1968) Spinal stenosis, a cause of cauda equina compression. Journal of Bone and Joint Surgery, 50-B, 606-618.

Teng, P., and Papatheodorou, C. (1963) Myelographic findings in spondylosis of the lumbar spine. British Journal of Radiology, 36, $122-128$.

Verbiest, H. (1954) A radicular syndrome from developmental narrowing of the lumbar vertebral canal. Journal of Bone and Joint Surgery, 36-B, 230-237.

Verbiest, H. (1955) Further experiences on the pathological influence of a developmental narrowness of the bony lumbar vertebral canal. Journal of Bone and Joint Surgery, 37-B, 576-583.

Verbiest, H. (1975) Pathomorphologic aspects of developmental lumbar stenosis. Orthopedic Clinics of North America, 6, $177-196$. 